\title{
Cellular response to UVA-B light depends on cellular age and chromatin structure
}

\author{
Bela Vasileva \\ Laboratory of Molecular Genetics \\ Institute of Molecular Biology "Acad. R. \\ Tsanev", Bulgarian Academy of \\ Sciences \\ Sofia, Bulgaria \\ belavas@outlook.com \\ Natalia Krasteva \\ Electroinduced and Adhesive Properties \\ Institute of Biophysics and Biomedical \\ Engineering, Bulgarian Academy of \\ Sciences \\ Sofia, Bulgaria \\ nataly@bio21.bas.bg
}

\author{
Dessislava Staneva \\ Laboratory of Molecular Genetics \\ Institute of Molecular Biology "Acad. R. \\ Tsanev", Bulgarian Academy of \\ Sciences \\ Sofia, Bulgaria \\ dessysta@gmail.com \\ George Miloshev \\ Laboratory of Molecular Genetics \\ Institute of Molecular Biology "Acad. R. \\ Tsanev", Bulgarian Academy of \\ Sciences \\ Sofia, Bulgaria \\ karamolbiol@gmail.com
}

\author{
Plamen Zagorchev \\ Department of Physics and Biophysics, \\ Faculty of Pharmacy, Medical University \\ - Plovdiv, Bulgaria \\ Plovdiv, Bulgaria \\ plamenz@gbg.bg \\ Milena Georgieva \\ Laboratory of Molecular Genetics \\ Institute of Molecular Biology "Acad. R. \\ Tsanev", Bulgarian Academy of \\ Sciences \\ Sofia, Bulgaria \\ milenageorgy@gmail.com
}

\begin{abstract}
Complex interactions among DNA and nuclear proteins maintain genome organization and direct its stability. Both chromatin organization and stability are crucial for the way DNA is organized, compacted and preserved but also bring about intricate processes for its dynamic reorganization. As the fifth class of histone proteins, the linker histones interact with DNA and other histones and thus take major part in maintaining genome stability and nuclear organization. Our recent results have proved that Saccharomyces cerevisiae linker histone - Hho1p, physically interacts with the actin-related protein 4 (Arp4). The abrogation of this interaction through the deletion of the gene for the linker histone $-\mathrm{HHO1}$ in arp4 mutant cells leads to global changes in chromatin compaction. Results show that the healthy interaction between the yeast linker histone and Arp4p is critical for maintaining genome stability and for controlling cellular sensitivity to different types of stress, particularly UVA/B stress. The double mutant yeast cells exhibit cellular characteristics of prematurely aged cells. They have completely abolished higher-order chromatin organization, die young and are subtler to different types of stress. This unambiguously proves the role of linker histones and chromatin remodelling in ageing by their cooperation which allows us to hypothesize that the linker histones are essential for maintaining higher-order chromatin compaction and thus preserving genome stability during ageing.
\end{abstract}

Keywords - chromatin, ageing, linker histones, chromatin remodelling, Arp4, UVA/B stress, genome stability

\section{Introduction}

The molecule of DNA is compacted in the constrained nuclear compartment through binding with histone proteins which allows it to make an intricate nucleoprotein complex, known as chromatin. Chromatin is organized in nucleosomes which are composed of four pairs of the core histones - H2A, $\mathrm{H} 2 \mathrm{~B}, \mathrm{H} 3$ and H4, around which 146 bp of DNA are wrapped (Luger et al., 1997). Outside of the nucleosome though binds a fifth class of histone proteins, recognized also as the family of linker histones or H1. The role of the linker histones is to stabilize the nucleosome by transforming it in a larger unit called chromatosome. A more important function of $\mathrm{H} 1$ histones is their engagement in the building and maintenance of the higher-order chromatin structures like the putative 30 $\mathrm{nm}$ fibres and structures above it corresponding to differently sized chromatin loops (Georgieva et al., 2012). As a reflection of its complexity chromatin is involved in processes like DNA replication, chromosome segregation, DNA repair and others. To fulfil these functions, it goes through various types of epigenetic modifications like DNA methylation, histone modifications and non-coding RNA binding (Allis et al., 2007; Georgieva et al., 2016). Chromatin secondary structures have great impact on cellular fate. Structural changes in the way the genome is organized at these higher levels of chromatin compaction govern and moderate gene expression and by this modulate cellular response to intrinsic and extrinsic signals. This determines the way cellular programs are performed and also controls cellular normality. Many diseases and other pathologies like cancer, ageing, ageassociated diseases and others have been linked with alterations in the structural organization of chromatin and its epigenetic make-up. Although these changes have been linked with aberrant cellular programs little yet is known about the molecular mechanisms underlying cellular adaptability to different types of stress. Here, we show our recent results which demonstrate the role of two chromatin players in the process of cellular ageing and stress resilience.

\section{Experimental}

Yeast strains

Wild type (WT) - MATa his4-912 ade2 his4-912 lys2128 can1 trp1 ura3 ACT3

hho1s (in the text appears as hho1delta) - MATa his4-912 ade2 his4-912 lys2-128 can1 trp1 ura3 act3 yp1127C::K.L.URA3

arp4ts26 (designated in the text as arp4) - MATa his4-912 ade2 lys2-128 can1 leu2 trp1 ura3 act3-ts26

arp4ts26 $\Delta$ hho1 (in text denoted as arp4 hho1delta) MATa his4-912 ade2 lys2-128 can1 leu2 trp1 ura3 act3ts26 yp1127C::K.L.URA3 


\section{CLS of S. cerevisiae}

The CLS of $S$. cerevisiae was examined according to (Longo and Fabrizio 2012, Uzunova et al. 2013).

\section{UVA/B irradiation of cells and Colony Forming Units (CFU)} assays

Yeast cells were cultivated in minimal medium and probes of them were taken at the 4th, 24th, 72nd hours and 9th day of cultivation. One hundred cells were spread on each Petri dish. These were then irradiated with UVA/B light for 3 or 30 minutes. The used source of UVA/B was a $15 \mathrm{~W}$ Cleo lamp, with the help of which an energy dose of $2.56 \mathrm{~mW} / \mathrm{cm} 2$ was obtained. The irradiation was followed by a 2-day recovery period at $30^{\circ} \mathrm{C}$ on a rich YPD plate. After this time the number of formed colonies was counted and the percentage of viable cells was estimated with a respect to the non-irradiated control.

\section{Fluorescence Activated Cell Sorting (FACS) analysis}

FACS analysis was performed according to (Georgieva, et al. 2012). Several changes were made: cells were fixed with $100 \%$ ethanol; sonication lasted for 20 seconds at $50 \%$ power; cells were incubated with RNase A $(0.25 \mathrm{mg} / \mathrm{ml})$, after which they were centrifuged for $4 \mathrm{~min} / 5000 \mathrm{~g}$. This was followed by a pre-staining with propidium iodide and probing at a BD FACSCanto apparatus. Quantification of the results was made by a FlowJoV10 software.

\section{Gene expression analyses}

Aliquots were taken and total RNA was isolated. Briefly, cells were washed with $1 \mathrm{ml}$ of ice-cold RNase-free water and collected by centrifugation at $1500 \mathrm{~g}$. Cell pellet was resuspended in $400 \mu \mathrm{l}$ of TES solution (10 mM Tris, $\mathrm{pH} 7.5$, $10 \mathrm{mM}$ EDTA, $\mathrm{pH} 7.5$ and $0.5 \%$ SDS) followed by addition of $400 \mu \mathrm{l}$ of pre-warmed at $65^{\circ} \mathrm{C}$ acid phenol and incubation for $60 \mathrm{~min}$ at $65^{\circ} \mathrm{C}$ with $10 \mathrm{sec}$ vortexing at every $15 \mathrm{~min}$. After centrifugation for $15 \mathrm{~min}$ at $10000 \mathrm{~g}$ the purification of nucleic acids continued with three subsequent extractions with $400 \mu \mathrm{l}$ of hot acid phenol each and a final extraction with 400 $\mu \mathrm{l}$ chloroform. Nucleic acids were precipitated at $-20{ }^{\circ} \mathrm{C} \mathrm{ON}$ with three volumes of cold $100 \%$ ethanol and $1 / 10$ volumes of $3 \mathrm{M}$ sodium acetate, $\mathrm{pH}$ 5.2. Total RNA was then washed with $70 \%$ ethanol, dried and dissolved in RNase-free water. The concentration and purity of the isolated total RNA was determined using NanoDrop ${ }^{\circledR}$ ND-1000 spectrophotometer.

The level of the ScACT1, ScCDC28 and ScRAD 9 mRNAs was analyzed by real - time reverse transcriptase PCR (RTqPCR). $1 \mu \mathrm{g}$ of DNase I-treated total RNA was reverse transcribed into cDNA using oligo-dT18 primer and RevertAid $^{\text {тм }}$ H Minus First Strand cDNA Synthesis Kit (Fermentas) according to manufacturer's instructions.

Gene expression analyses were performed with Maxima ${ }^{\circledR}$ SYBR Green qPCR Master Mix (Fermentas) on Rotor Gene 6000 (Corbett LifeScience) following manufacturers' protocols. All primer pairs were designed through SGD Web Primer design tool. qPCR was performed in duplicate, using
$1 / 40$ th $(25 \mathrm{ng})$ of the cDNA template and $0.2 \mu \mathrm{M}$ each of the forward and the reverse gene-specific primer in a $20 \mu \mathrm{L}$ reaction mixture. Cycling conditions used for all primer sets consisted of an initial denaturation at $95^{\circ} \mathrm{C}$ for $10 \mathrm{~min}$ and 45 cycles of: $95{ }^{\circ} \mathrm{C}$ for $15 \mathrm{~s}, 60^{\circ} \mathrm{C}$ for $60 \mathrm{sec}$. The specificity of the resulting amplicons was confirmed by melting curve analysis and agarose gel electrophoresis.

The expression of each gene was normalized to the reference gene ScACT1. Relative quantification expression levels were calculated by comparative CT method via RotorGene Q Series Software 1.7.

\section{Results and Discussion}

The proliferative potential of the yeast mutant cells was assessed by FACS analysis and was compared to the control wild type cells. Cell aliquots were taken at the four time points: day 1, day 2, day 3 and day 9. Percentage of cells in different phases of the cell cycle has been calculated by means of specialized software FlowJo V10. The results from these experiments showed that arp4 hholdelta double mutant cells are short-lived with impaired proliferation potential. Their vacuolar morphology was changed and resembled the morphology of prematurely aged cells. Cells from control cultures and cells exposed to replicative, cold temperature and oxidative stress were plated on solid rich media and were cultured at $30^{\circ} \mathrm{C}$ for three days. CFUs (colony forming units) were counted. Results showed that the double mutant cells could not survive the applied stress conditions, thus suggesting increased stress sensitivity and lack of resilience.

\section{conclusions}

Hholp interaction with Arp4p is crucial for yeast chronological lifespan. Abrogation of the interaction between the yeast linker histone Hholp and Arp4p leads to premature ageing phenotypes in the mutant cells. The cells without the linker histone and bearing a mutation in ARP4 die young. These chromatin mutant cells possess changed vacuolar morphology at early stages of their lifespan. The lack of proper chromatin structure in the mutant cells make them more prone to different types of stress.

\section{ACKNOWLEDGMENT}

The work is sponsored by the Bulgarian Science Fund Grant number: DN 11/15 and NATO Science for Peace and Security programme [grant number: NATO SPS MYP G5266].

\section{REFERENCES}

[1] Longo and Fabrizio 2012

[2] Uzunova, K., et al. 2013

[3] Georgieva, M., et al. 2012

[4] Luger, K., et al., 1997

[5] Allis, D., et al., 2007

[6] Georgieva, M. et al., 2016 